\title{
PROYECTOS DE VIDA \\ Y ACOMPAÑAMIENTO A LAS PERSONAS CON DISCAPACIDAD INTELECTUAL: ENFOQUE ÉTICO
}

\section{Life projects and accompaniment of persons with intellectual disabilities: ethical perspective}

Xabier EtXeberRia Mauleon

Universidad de Deusto. Centro de Ética Aplicada

xetxeman@deusto.es

Recepción: 18 de septiembre de 2017

Aceptación definitiva: 13 de abril de 2018

Resumen: Hay muchos estudios en torno al apoyo a las personas con discapacidad intelectual en el ejercicio de su autonomía, pero son muy escasos los que se centran en ese apoyo cuando la persona busca concretar tal ejercicio en sus proyectos de vida. Este artículo aborda con enfoque ético el acompañamiento en el momento de la elucidación y la realización de los proyectos. Para ello, se comienza aclarando la intención que lo alienta y resaltando la relevancia moral de lo bueno -no solo de lo justo-, se presentan a continuación las coordenadas que delimitan el campo de los proyectos vitales y se pasa luego a desarrollarlas y a considerar cómo pueden ser tenidas en cuenta en dicho acompañamiento. Concretamente, se analiza la conexión de los proyectos de vida buena con las virtudes, las prácticas, los planes de vida y las opciones de sentido.

Palabras Clave: personas con discapacidad intelectual; proyectos de vida; apoyos; virtudes; propuestas de sentido.

ABSTRACT: Although there is plenty of research about the support for the exercise of autonomy of persons with intellectual disabilities, there is scarcely any which focuses on this support when the individual materializes such exercise on his own life project. This paper addresses from an ethical perspective the accompaniment during the definition 
and development of life projects. Therefore, it begins clarifying the intention sustaining it and enhancing the moral relevance of what is good -not only of what is fair-. It then presents the coordinates which define life projects contents and develops them consequently, considering too how they must be taken into account in such accompaniment. Specifically, the connection between good life projects and virtues, practice, life plans and meaningful life options is analyzed.

KEY WORDS: persons with intellectual disabilities; life projects; supports; virtues; meaningful life proposals.

\section{Intención de este escrito ${ }^{1}$}

L

a “Convención de derechos de las personas con discapacidad” ha consagrado, con toda justicia, el enfoque de derechos en el reconocimiento de estas personas, frente a enfoques menospreciadores y paternalistas precedentes. En él se contempla un posible momento de "acompañamientos" y “apoyos", personales e institucionales, a los que ellas tienen derecho cuando se precisan para el mayor ejercicio de su autonomía (2017). Se entiende que, protegida así la capacidad de autodeterminación, esta será actualizada por cada persona para perseguir una vida lograda a través de la realización de sus proyectos libremente elegidos, para los que el disfrute de los derechos sociales, garantizado por las instituciones públicas, y los apoyos pertinentes tienen que proporcionar los bienes y recursos básicos necesarios. Al hilo de este supuesto se tiende a señalar un límite, confesado o no, a tales acompañamientos y apoyos: no tendrían que "inmiscuirse" en la clarificación de los planes de vida de estas personas, que deberían dejarse a su libre arbitrio.

Una reserva similar puede encontrarse en propuestas éticas muy relevantes en las últimas décadas, las cuales han destacado que la tarea propia del saber ético, a la que debe ceñirse, es la de ofrecer principios y orientaciones para garantizar cívicamente el respeto a las libertades individuales y la existencia de las condiciones sociales de posibilidad para su ejercicio. Piénsese, por ejemplo, en la teoría de la justicia de Rawls o en la ética discursiva de Habermas. El primero (Rawls, 1979) confiesa expresamente que se impone la prioridad de lo justo universalizable, esto es, de los principios imparciales de convivencia, sobre lo bueno, los proyectos de felicidad en su legítima pluralidad, que cada uno podrá considerar libremente cuando se garantice públicamente lo justo. En cuanto a Habermas (1991 y García Marzá, 1992), distingue claramente: a) cuestiones de justicia, susceptibles de acuerdos que expresan intereses generalizados con validez universal, a las que hay que aplicar la ética dialógica que propone; y b) cuestiones que llama “evaluativas” o "existenciales", las que remiten a variados ideales de realización o vida buena, que dependen de tradiciones concretas. Sobre estas últimas, concluye, solo caben deliberaciones en contextos particulares, debiendo exigírseles que no quebranten las primeras, que son a

1 Tiene su origen en una sesión formativa - “De los derechos a los proyectos de vida”- realizada en APROCOR, ALEPH y PAUTA (Madrid, noviembre de 2016) y en GAUTENA (San Sebastián, marzo de 2017). 
la vez su marco posibilitador y limitativo. Como puede verse, en teorías éticas como estas domina el enfoque deontológico decisivamente marcado por Kant (1973), el focalizado en imperativos y derechos, que suele estar acompañado del temor a que si nos introducimos con contundencia en el debate en torno a cuestiones de vida buena podremos acabar siendo impositivos.

Un enfoque así posterga potentes planteamientos teleológicos de la ética que tienen en Aristóteles (1988) su precursor más relevante. Cuando se enfatizan, nos vienen a decir que el momento primario del saber ético y de su puesta en práctica es el de la búsqueda de la vida buena, feliz, lograda -para la que ofrecen propuestas y orientaciones varias-, y que, de algún modo, la dimensión normativa tiene que estar sometida a ella. Sin necesidad de ir tan lejos, creo que lo que debe defenderse es la articulación compleja entre la perspectiva teleológica -centrada en la finalidad-y la deontológica - centrada en el deber- de la ética: la primera convocándonos a reflexiones en torno a esa vida buena que puedan inspirar y ayudar a discernir los proyectos personales, la segunda recordándonos la relevancia de la autonomía asentada en la dignidad, que siempre debe ser respetada y potenciada al tratar de diseñar y poner en práctica tales proyectos.

Este enfoque articulador de la ética es el que se asume en estas líneas, para aplicarlo a la temática del acompañamiento y apoyo a las personas con discapacidad intelectual. Desarrollarlo en toda su amplitud pide que se considere el acompañamiento tanto en el ejercicio y potenciación de su autonomía como en la aplicación de esta a la formulación y realización de sus proyectos de vida; además, en su imbricación. Dado que en otros lugares ya he reflexionado sobre lo primero (2016) y que sobre ello hay muchos y diversos estudios, aquí me ceñiré a presentar las coordenadas que deben ser tenidas en cuenta al acompañar a las personas con discapacidad intelectual en sus proyectos de vida, en los que dan contenido material a su autodeterminación.

Antes de abordar esta tarea se impone, de todos modos, una advertencia, a fin de evitar malentendidos. No se trata de que las personas con discapacidad intelectual necesitarían que se les ofrecieran, con el acompañamiento pertinente, propuestas éticas en torno a la felicidad para diseñar sus proyectos personales, mientras que el resto de personas no lo requerirían. La referencia a la ética de la vida buena es igualmente conveniente para todas las personas, solo que cada una tendrá que remitirse a ella desde sus circunstancias, una de las cuales, la que aquí se tendrá presente, es la condición de discapacidad. Formulando esto de otro modo, puede decirse que las personas con discapacidad tienen el mismo derecho que las demás a tener ante sí planteamientos éticos consistentes sobre la vida buena a la hora de afrontar sus proyectos vitales; porque, como en todas, estos quedarán enriquecidos; y porque no hacerlo supone discriminación y quizá, trasfondos de paternalismo -sería algo que “les desbordaría”-. Esta convicción se refleja en la exposición que sigue, en la que la consideración del acompañamiento a las personas con discapacidad irá precedida de una presentación de la ética de la vida buena válida para cualquier persona en cualquier circunstancia. 


\section{Lo bueno en relación con lo justo}

Hablar de proyectos de vida es, éticamente, hablar de lo bueno, de la vida feliz o realizada. La condición general de posibilidad éticamente exigible para poder diseñar esos proyectos con las dilucidaciones necesarias y de realizarlos con los recursos requeridos es la de disfrutar de los derechos civiles, políticos y sociales. Se da así una complementariedad: los derechos sin los proyectos son vacíos; y los proyectos sin los derechos, o bien se frustran pura y simplemente, o bien se expresan en forma de injusticias y deshumanizaciones, para otros -cuando se los imponemos-e incluso para nosotros mismos.

En cualquier caso, como ya se avanzó, las propuestas éticas no deben reducirse a la dimensión de lo justo, tienen que implicar también la dimensión de lo que consideramos bueno para nosotros, felicitante. No aisladamente, sino insertados en relaciones intersubjetivas y en grupos sociales de referencia e identidad.

Ahora bien, así como la orientación a lo justo persigue expresarse de modo unitario y universalizable, la orientación a lo bueno no debe ignorar que implica intrínsecamente un pluralismo de propuestas. $\mathrm{O}$, dicho de otro modo, el pluralismo legítimo es discreto en lo justo (interpretaciones varias asumibles de los derechos humanos, sobre las que debatimos cívicamente con unas pautas democráticas compartidas), mientras que es intenso en lo bueno, al estar ligado a múltiples tradiciones culturales, concepciones antropológicas, mundos de sentido, historias personales, etc. En lo justo queremos plasmar la normatividad obligante para una convivencia sin opresiones ni marginaciones, mientras que lo bueno remite a la vida que anhelamos, al deseo de realizarla, al cual la diversidad le es consustancial.

A veces se extrae de esto la conclusión de que en el ámbito de lo bueno domina el relativismo puro, que invitaría a elegir el proyecto que nos apetece -si no hiere directamente lo justo- sin que tengamos que autoimponernos procesos de discernimiento. Pero la ética de la vida buena nos reclama estos procesos, pues aunque todos los proyectos vitales que respetan lo justo están permitidos, no todos se nos muestran igualmente buenos: porque unos sirven mejor a la justicia que otros (mostrándose la porosidad entre lo deontológico y lo teleológico) y porque hay modos de vida feliz que son más plenificantes de lo humano que otros.

El último argumento es ciertamente peligroso, porque puede dar lugar a que autoridades de diverso tipo decidan en lugar de nosotros qué proyecto de vida es mejor y traten de imponérnoslo, supuestamente por nuestro bien. Desgraciadamente, esto ha sido algo muy común, y deberemos preguntarnos en qué medida sigue estando presente en los tutelajes que se realizan a las personas con discapacidad intelectual. Frente a esta amenaza, se impone recordar que un proyecto impuesto descarada o sutilmente no es proyecto personal, y aquí estamos hablando de proyectos personales, libres. Ahora bien, este riesgo no invalida la exigencia de autoclarificación de los propios proyectos - para elegir el mejor para nuestro contexto- y la posible conveniencia de invitar a otros a esa clarificación y acompañarles en ella. Simplemente reclama que no haya ni frivolidad en la autoelección -por exigencia de autenticidad personal- ni imposición externa -por respeto a la dignidad-. Lo cual pide que en las interpelaciones 
mutuas que nos hagamos en torno a nuestros proyectos de vida no utilicemos como argumentos más que el diálogo que expresa una razonabilidad que no se impone y el testimonio que aporta experiencias personales en las que lo defendido se "prueba" a través de las vivencias de quien lo defiende.

Pensemos, por ejemplo, en diseños posibles de vida realizada focalizados en fines globales como estos: vida de éxito social, vida intensa que persigue la acumulación máxima de experiencias, vida comprometida por la justicia, vida auténtica acorde con aquello que nos sentimos llamados a ser; etc. ¿No es cierto que caben aquí multitud de argumentaciones y testimonios interpeladores entre quienes optan en la práctica por cada uno de esos fines, en unos casos excluyentes entre sí y en otros no, que tanto inciden en los proyectos concretos?

Preguntas como esta nos conducen a que formulemos la que es central para este escrito: las relaciones de acompañamiento y apoyo a las personas con discapacidad intelectual ¿deben contemplar este horizonte de lo bueno o hay que ceñirse únicamente a apoyar la capacidad de autodeterminación y la realización de lo justo en ellas? Avanzo mi respuesta afirmativa, aunque las razones se harán perceptibles cuando se explicite lo que un proyecto de vida buena tiene que considerar.

\section{Las coordenadas de la vida buena}

1. Al fin (telos) genérico de la vida buena humana, que perseguimos de modo concreto con nuestros proyectos de vida, Aristóteles lo llama eudaimonía. Solemos traducir este término por "felicidad", pero, como muy bien subraya Thiebaut (2005), se trata de un concepto que tiene un contenido holista muy marcado al sintetizar bien-ser, bien-hacer y bien-estar; algo que no queda reflejado en nuestra actual consideración de la felicidad. Es un contenido, además, que debe ser situado en las circunstancias precisas de cada uno, concretado con la guía de la prudencia, contemplando el horizonte de la totalidad de la vida, e implicando la subjetividad, la intersubjetividad y la polis.

Pues bien, en buena medida puede decirse que Aristóteles nos ofrece con esta categoría las coordenadas generales de la vida buena, de los proyectos de vida. Reasumiéndolas, purificándolas éticamente y actualizándolas, pueden formularse de este modo:

- Coordenada del bien-ser. Nuestra felicidad está en nuestro modo de ser, concretamente, dirá Aristóteles, en nuestro modo virtuoso de ser, el que realiza nuestra excelencia (areté) como humanos. Nuestros proyectos personales de vida deben incluir decisivamente la construcción de nuestro "carácter" moral.

- Coordenada del bien-hacer. En parte emana del bien-ser, en parte ayuda a construirlo. Hoy podríamos concretarlo en tres subcoordenadas: a) opción personal por las prácticas -categoría que se presentará luego- en las que concretar la excelencia de nuestras acciones implicadas en ellas; b) diseño y persecución de planes de vida que, incluyendo las prácticas, imbrican además diversos proyectos parciales sobre aspectos concretos de la vida; c) opción por referentes de 
sentido que inspiran y sostienen esas apuestas por las virtudes, las prácticas y los planes de vida.

- Coordenada del bien-estar. Remite a las condiciones externas de la vida feliz, cuya posesión, de todos modos, nos da además unas sensaciones agradables que también forman parte de la felicidad, aunque en modo alguno esta deba ser reducida a ellas. En una sociedad justa las condiciones de bienestar pueden lograrse en parte con el ejercicio de prácticas como las profesiones y en parte con el disfrute de los derechos sociales. Aunque siempre cabe la "mala fortuna", por ejemplo, en forma de enfermedad crónica incurable de la que nadie es responsable, que los derechos sociales únicamente pueden paliar. En este caso, el reto es afrontarla lo más positivamente posible desde las virtudes y los mundos de sentido.

2. Estas son, pues, las coordenadas de la vida buena que convendría que tuviéramos presentes todas las personas a la hora de diseñar y realizar nuestros proyectos vitales. ¿En qué medida debemos reasumirlas en los acompañamientos y apoyos a las personas con discapacidad intelectual?

En primer lugar, en esos acompañamientos hay que estar abiertos a todas las coordenadas citadas, aunque, según las circunstancias, los momentos e incluso los sujetos acompañantes (familia, profesional, voluntario, etc.), nos toque centrarnos más en unas que en otras, más en unos modos que en otros. Se verá en lo que sigue lo que esto puede significar.

En segundo lugar, es importante ser conscientes de que en estos acompañamientos serán significativas no solo las convicciones deontológicas de quienes acompañan, sino también sus formas de abordar sus propios horizontes de vida buena, aunque tengan que serlo de modo diferente -la conexión con lo obligante solo cabe en lo primero-. Globalmente hablando, acompañará mejor quien tiene la experiencia de construir proyectos vitales personales ética y humanamente sólidos que, por ser tales, nunca serán impositivos, sino acogedores de la realidad y la libertad del otro.

Precisadas de este modo las coordenadas de la vida buena y apuntada su proyección a las personas con discapacidad intelectual, pasemos a desarrollarlas.

\section{Vida buena y virtudes}

1. La expresión ética del bien-ser como humanos, nuestra excelencia, se plasma en la configuración de nuestro modo personal moral de ser. Y este, a su vez, se concreta en nuestro ser acorde con las virtudes, esto es, las excelencias, como se dice en griego (areté). Estas son a la vez una dimensión decisiva de la felicidad y una vía para ella. Hoy, en nuestro contexto cultural, la categoría "virtud" no suele ser estimada, pero por los prejuicios adheridos a ella y porque tiende a ser mal concebida. Estas no son razones para rechazarla, sino para purificar la percepción de ella. La clásica definición de Aristóteles (1988), actualizada pertinentemente, puede ayudarnos a ello.

Este autor destaca, para empezar, que las virtudes, en su expresión más propia, son nuestro modo excelente de ser humanos (no "se tiene" generosidad sino que "se 
es” generoso), son nuestra plenitud, la realización positiva de lo que podemos ser, de nuestro fin. Configuran nuestro “carácter moral”, con su proyección intersubjetiva, comunitaria y cívica. Lo configuran, además, a nuestra manera, teniendo presentes nuestro "carácter psicológico" y nuestros contextos culturales. Por eso, precisamente, teniendo una dimensión universalizable (piénsese, por ejemplo, en la paciencia) tienen concreciones particulares, tanto culturales como personales, respecto a las que se puede entrar en diálogo. Al ser “modos de ser” impregnan y unifican toda nuestra realidad personal: corporalidad y psique; intelecto, memoria, imaginación, afectos, motivaciones, para bien propio y de los demás. Al ser modos de ser que "nos plenifican”, se cultivan con gozo, aunque a veces nos cuesten: las virtudes en cuanto tales no pueden imponerse externamente, "debemos" autoimponérnoslas, pero porque percibimos que expresan nuestra realización, a lo que ayuda mucho el que nos sean presentadas bien, con argumentaciones y testimonios.

Es especialmente relevante y significativa su conexión con las emociones, hasta el punto de que las virtudes pueden considerarse modulaciones estables de los sentimientos orientadas al bien. Como dice Aristóteles, las emociones virtuosas se expresan "cuando es debido, por aquellas cosas y hacia aquellas personas debidas, por el motivo y la manera que se debe y como se debe” (1988: 168). Piénsese, por ejemplo, en la virtud de la indignación. El que se integre así el sentimiento éticamente madurado hace que la virtud sea movilizadora - mueven las emociones, no los meros principios- y sea internamente acogida como buena -no forzada-.

Que la virtud sea modo de ser supone que no es transitoria, que permanece en el tiempo, a pesar de las adversidades y en la diversidad de contextos. Aristóteles llega a decir: "En ninguna obra humana hay tanta estabilidad como en las actividades virtuosas" (1988: 149). Pero añadiendo: con flexibilidad similar a la del buen zapatero que hace siempre el mejor calzado con el cuero de que dispone. Esto es, se trata de una durabilidad en la flexibilidad creativa (piénsese, por ejemplo, en la fidelidad). De nuevo, gran versatilidad entre lo constante y universalizable del corazón de la virtud -lo fundamental de su disposición-y sus plurales contextualizaciones históricas, sociales y personales.

Primariamente, la virtud no es, pues, una propiedad de las acciones sino del sujeto, excelencia moral de su carácter. Pero, evidentemente, implica acciones buenas acordes con cada virtud. Respecto a estas es una disposición permanente hacia ellas, nos "capacita” y da fuerza para realizarlas, nos conduce con constancia a ellas (se muestra como hábito) y se autentifica en ellas. En la práctica, hay circularidad creativa entre hacer lo virtuoso porque se es virtuoso y ser virtuoso porque se van haciendo acciones virtuosas. Piénsese, por ejemplo, en la virtud de la escucha.

El contenido de estas acciones se precisa como término medio entre dos extremos viciosos, no en cuanto a la excelencia -es el extremo mejor-, sino en cuanto a la expresión de las emociones y las acciones. Un modo habitual de falsear las virtudes al invitar a ellas, desprestigiándolas, ha sido el de confundirlas con uno de sus extremos viciosos. Piénsese, por ejemplo, en la humildad. Debe advertirse, de todos modos, que el término medio es relativo a nuestras condiciones y circunstancias: se define contextualizadamente con la guía de la prudencia. En este sentido, es un reto para la creatividad. 
Sin la elección personalizada por ser virtuoso no hay virtud, aunque haya conducta, por conformismo o por inclinación natural. Y esta elección está determinada por la razón que integra el sentimiento: la virtud implica "deseo -atracción, motivación- deliberado -conformado por la razón-”, “deseo inteligente” (Aristóteles, 1988: 270). Eso es el ser humano realizado, síntesis de intelecto, sentimiento, elección. Quien elige una virtud así, por ser virtud, tendencialmente las elige todas, consciente de que es la interrelación entre ellas la que las potencia y purifica. En esta purificación el aspecto más básico es el que aporta el respeto como virtud -“siento respeto por ti"-, remitido al reconocimiento de la dignidad del ser humano (algo extraño al mundo aristotélico).

Es importante destacar que en Aristóteles las virtudes están enmarcadas en la polis, que por tanto tienen, diríamos ahora, una perspectiva pública. Esto lo traducimos hoy distinguiendo virtudes públicas, de convivencia cívica (la justicia, el respeto, la indignación cívica, etc.) y virtudes de alcance privado (la humildad, la paciencia, la mansedumbre, etc.). Aunque al analizarlas, al verlas encarnadas en el carácter moral de las personas, constatamos que esa distinción tiende a difuminarse: la mansedumbre tiene una marcada expresión pública en forma de no violencia, la compasión es también decisiva para afrontar cívicamente la victimación, la sobriedad se nos ha hecho virtud cívica relevante ante la crisis ecológica, etc. Quizá acabe siendo más ajustado afirmar que la mayoría de las virtudes tienen la posibilidad de un ejercicio público y privado de ellas, según los contextos.

De las virtudes se podrían decir muchas más cosas. Además, la clarificación sobre ellas aumenta cuando se describe lo nuclear de virtudes concretas relevantes para las situaciones consideradas. Dado que no es este el lugar para tales tareas, el lector puede consultar fuentes bibliográficas en las que se abordan (por ejemplo: Camps, 1990; Comte-Sponville, 1998; Etxeberria, 2005 y 2012; MacIntyre, 2001).

2. Pasemos ahora a exponer cómo pueden ser tenidas en cuenta las virtudes en el acompañamiento a las personas con discapacidad intelectual como apoyo a sus proyectos de vida.

Para empezar, quien ofrece relaciones de apoyo con estas personas debe preguntarse si tiene alguna función que cumplir en la maduración en las virtudes de la persona a la que acompaña, en forma tal que plenifiquen su modo de ser, que la hagan ser buena. Y deberá comenzar respondiéndose que tiene al menos una, que se le impone fácticamente aunque no quiera. Como ya subrayó Aristóteles, todos nos educamos en las virtudes a través de la "imitación” de personas significativas, que para que sea positiva debe ser lúcida, crítica, creativamente personalizada. Quien acompaña a las personas con discapacidad intelectual es una de estas personas -le guste o no-, ejerciendo esa función de referencia que tiene que asumir para ejercerla bien.

Esta dinámica de imitación, en la que todos los humanos entramos, puede sonar a sumisión. Si es asociada con la potenciación de la lucidez y la creatividad en quien “imita”, tal sospecha decae. Pero hay además otro elemento que la desvanece definitivamente: la disposición, por parte de quienes acompañan, a aprender de la ejemplaridad en virtudes de las personas acompañadas. Hay una virtud que ayuda a ello, la de la humildad. 
No se trata, por supuesto, de que haya que buscar ponerse como ejemplo, algo peligroso. Se trata, nada más y nada menos, que de tener la relación ética debida con las personas a las que acompañamos, que impregne el modo de relación que nos corresponde como familiar o profesional o gestor o voluntario. Pues bien, en las relaciones de apoyo y acompañamiento, a veces nos encontramos con dilemas o problemas morales que piden discernimiento a partir de los principios, para decidir qué debemos hacer. Pero en lo cotidiano, en lo de todos los días, la oferta positiva de apoyos será excelente únicamente si sintetiza en quien los ofrece la expertez que le es propia por el lugar que ocupa -la función que tiene- y el cultivo de las virtudes. Por eso es tan decisiva la referencia a las virtudes de quien pretende acompañar y apoyar. De la asunción de esta referencia brotará espontáneamente la ejemplaridad de la que hablábamos. Piénsese, para que esto quede manifiesto, en una relación alentada por virtudes como estas, formando racimo entre ellas: respeto, reconocimiento, humildad, veracidad, escucha, dialogalidad, compasión, indignación-justicia, generosidad, serenidad, paciencia, mansedumbre, confianza, esperanza, perseverancia, prudencia... A quien acompaña, esto podría parecerle de una exigencia desmesurada. Pero su perspectiva cambia si lo ve como un horizonte, como un proyecto personal, al que avanzará con dificultades y fallos, en el que ayudando a la plenificación de otros se plenifica a su vez a sí mismo, es feliz. Sin que aquí haya ninguna instrumentalización de nadie, sino una solidaridad básica compartida en la construcción de la felicidad.

Además de esta colaboración implícita a que la persona con discapacidad madure en virtudes, quien acompaña puede preguntarse si tiene que ofrecer una colaboración explícita, alentando que la persona acompañada asuma expresamente el cultivo de la virtud como parte relevante de su proyecto vital. Considero que la respuesta tiene que ser afirmativa. Esta incentivación del cultivo de la virtud, con los modos y ritmos que se precisen, tiene que formar parte expresa de los procesos de aprendizaje en todos los contextos en los que se dan (tratando de que sean contextos de educación inclusiva por lo que se refiere a la educación reglada), alentados por los diversos responsables de ellos. Será necesario, entonces, tener muy presente la pedagogía de la virtud que, junto a la ya citada expresión de imitación personalizada, contempla otras como la del aprendizaje cognitivo-emotivo-motivacional a partir de relatos, la educación en sentimientos o el aprendizaje a partir de la praxis.

\section{Vida buena y "prácticas"}

1. "Práctica" es una categoría propuesta por MacIntyre (1987). Se da especialmente en los ámbitos de las profesiones, del arte y de los juegos, en los que todos estamos implicados. Toda práctica (tomemos como ejemplo la práctica médica) remite a patrones de excelencia que le son propios (tiene un bien interno en el que debe mostrar su excelencia, en el ejemplo, prevenir y curar la enfermedad y acompañarla cuando es incurable), definidos en función de ideales sociales de perfección enraizados en una tradición viva (podemos remontar esta práctica al menos hasta Hipócrates), suponiendo actividades cooperativas con reglas establecidas socialmente y con implicaciones institucionales (desde el hospital hasta la OMS). 
A través de determinadas prácticas (como en la medicina, no así en la práctica del ajedrez como aficionado) podemos lograr bienes externos a ellas (en especial, dinero, prestigio, poder). Son legítimos siempre que se subordinen a los bienes internos. Si sucede al revés, que estos están al servicio de los externos, son puramente instrumentalizados, se produce la corrupción de la práctica.

Es innegable que las prácticas forman parte de nuestra vida buena, realizada, en su sentido moral, y que, en condición de tales, merecen ser incluidas en nuestros proyectos vitales. Posibilitan una ajustada estima de nosotros mismos como actores de esas prácticas; fomentan la expansión de rasgos personales valiosos (piénsese en la práctica de cualquier juego para el aficionado); podemos realizar a través de ellas un bien social (claro en las prácticas profesionales si no se corrompen); nos insertan en relaciones variadas con otras personas con todas las exigencias morales y enriquecimientos que ello supone, y pueden aportarnos recursos, a través de los bienes externos, en relación con el bienestar (como ocurre con estas últimas prácticas). Piden, por supuesto, honestidad con el bien interno y conciencia lúcida de sentirlas adecuadas para lo que somos, lo que podemos y lo que queremos hacer.

2. ¿Cómo tener presente esta categoría de práctica en la relación de acompañamiento y ayuda a las personas con discapacidad intelectual, en su diseño y realización de sus proyectos de vida?

En primer lugar, realizando bien el que acompaña su propia práctica. Las profesiones de atención son prácticas, de las que conviene definir sus bienes internos, como también lo son las actividades de gerencia y gestión. Ser padre o madre remite en parte a una práctica, aunque en otra parte significativa la desborda. La idea básica es que quien realiza bien su práctica ayudará mejor en general y, concretamente, acompañará mejor a los demás a elegir la práctica que desean y a realizarla.

En principio, la práctica que queremos realizar debería ser elegida, con discernimiento respecto a nuestras capacidades (para el desarrollo de las cuales deben ofrecernos oportunidades), pero también en concordancia con aquello que nos sentimos llamados a ser y hacer (autenticidad con nosotros mismos), no por pura ambición respecto a los bienes externos que pueda proporcionarnos. Quien acompaña tiene el reto de apoyar ese discernimiento con modos estimulantes y no impositivos. Pero aquí aparece un serio problema. En sociedades con graves déficits en inclusión social, a los que son marginados, como es el caso de las personas con discapacidad intelectual, se les reducen drásticamente las posibilidades de elección. Lo que exige a quienes les apoyan -y a la ciudadanía en general- que luchen para hacer una sociedad más inclusiva, mostrándose así una nueva conexión entre lo deontológico de la ética y lo teleológico.

Esta observación vale sobre todo para las prácticas profesionales, para la inclusión laboral de las personas con discapacidad intelectual. En este campo queda muchísima tarea por hacer, mostrándose en ello cómo la sociedad puede truncar proyectos legítimos de vida que además, como en este caso, están conexionados con la justicia debida. De todos modos, el necesario compromiso en este campo no debe hacer ignorar que hay ámbitos de prácticas, los del arte y el juego, que podemos estimular con menos dificultades y que conviene promoverlos con la seriedad de la 
práctica. Quien acompaña a las personas con discapacidad puede preguntarse si está alentando con esta seriedad dichas prácticas, ajustándolas a los deseos y capacidades de los acompañados. Porque una buena inserción en ellas es claramente significativa para la vida buena, no es nada despreciable de cara a los proyectos vitales.

\section{Vida buena y planes personales de vida}

1. El proyecto global sobre la propia vida imbrica en él múltiples proyectos parciales, ligados o no a las prácticas: familiares, de amistad, de vida sexual, de procreación, de vida saludable, formativos, laborales, cívicos, lúdicos y de ocio, etc. Inicialmente, a la persona se le muestran como una nebulosa de ideales de realización (Ricoeur, 1996: para esto y parte de lo que sigue). Hay que ir abordándola con la categoría ética de la prudencia o sabiduría práctica, la que discierne, haciendo claridad, las iniciativas posibles (incluyendo los apoyos a los que se tiene derecho), las circunstancias sociales potenciadoras y condicionantes, las capacidades, el carácter personal, los ideales... También es preciso un trabajo de clarificación sobre el modo como los planes de vida pueden armonizarse entre sí, pues a veces compiten entre ellos. Normalmente, identificamos el proyecto vital con estos planes de vida, aunque aquí se está insistiendo en que hay que darle más amplitud.

Con el diseño y puesta en práctica de nuestros planes vitales situamos nuestra vida en un marco narrativo de identidad: nos definimos por el modo como nos vamos construyendo al ir realizándolos, algo que expresamos a través de un relato explícito o implícito. Es muy relevante que lo que vaya expresándose en él muestre y aliente la estima de sí mismo, como sujeto capaz de iniciativa y colaboración con otros. Se da aquí una circularidad virtuosa: porque nos estimamos hacemos confiadamente las opciones señaladas, $\mathrm{y}$ al ir haciéndolas aumentamos nuestra estima.

A los planes de vida en general se les pueden aplicar dos de las observaciones hechas a las prácticas: la sociedad no debería obstaculizarlos excluyendo a determinados colectivos del acceso consistente a ellos; y la persona, al hacer la elección, tendría que guiarse por la lucidez y autenticidad respecto a sí misma.

La vida buena, feliz, tiene mucho que ver con estos planes de vida en los que se expande nuestra iniciativa. Pero no debe ser percibida únicamente desde nuestra constitución como sujetos actuantes. Es clave que incluyamos en ella una adecuada gestión de la dimensión de receptividad. Esta tiene una expresión positiva en forma de acogida agradecida de todo lo bueno que nos ofrecen los demás, personalmente y a través de instituciones, gracias a lo cual esos planes de vida son posibles. Pero tiene también una expresión sufriente, en forma de fracasos: a veces por nuestra responsabilidad, en otras ocasiones por limitaciones inevitables, en otras por injusticias padecidas; cada causa pide una reacción específica que nos (re)construya.

Insistiendo un poco más en uno de estos aspectos: hay que tener clara conciencia de que el modo como nos construimos con estos planes de vida tiene una intensa relación con los otros, a través de receptividades de ellos, de aportaciones a ellos, de 
colaboraciones; tanto en el plano intersubjetivo como social y cívico, implicándose en esto último organizaciones sociales e instituciones públicas.

2. Tras esta presentación del lugar de los planes vitales en nuestra vida realizada, pasemos una vez más a preguntarnos cómo tenerlo presente en el acompañamiento que aquí se está considerando.

De nuevo, la tarea se hace mucho mejor si contamos -dimensión deontológicacon una sociedad inclusiva. Si hay graves lagunas en ella, forma parte del acompañamiento luchar para que estas se vayan reduciendo.

Ya a nivel individual, es muy importante: a) un acompañamiento en la clarificación personal de los planes de vida que se eligen, para que respondan tanto a la autenticidad (no hacer planes por pura imitación en la que hay trasfondos de sometimiento) como a la razonabilidad; b) una oferta de los apoyos necesarios para que puedan ir realizándose.

Cuando las personas con discapacidad intelectual se encuentran con distancias muy marcadas entre sus planes de vida deseados y las realizaciones de ellos, cuando se topan con el fracaso, la tarea de quien las acompaña es ayudarles a afrontarlo distinguiendo las tres causas antes citadas, muy diferentes entre ellas. Es una tarea que puede resultar dolorosa, pero que es imprescindible para que la persona no se hunda en el menosprecio de sí misma. Los planes de vida son en sí muy estimulantes, los fracasos en ellos pueden ser muy destructores, con frecuencia muy injustamente destructores cuando son causados por dinámicas de exclusión.

El que esto pueda suceder nos recuerda lo relevante que es potenciar y mantener la ajustada estima de sí mismo. Quien acompaña debe estar siempre atento a cómo se está dando en quien atiende. Y cuando constate que es muy baja, la primera tarea del acompañamiento, en sí dirigido a apoyar los planes de vida, pasa a ser la de alentarla al alza, sin engaños, con dinámicas sólidas. A veces puede ser muy difícil, pero es ahí donde toca dinamizar apoyos alentados decisivamente por las virtudes.

\section{Vida buena y opciones de sentido y de valor}

1. Las propuestas de sentido, con los valores y los fines de plenitud que incluyen, son los referentes de significación y fundamentación de la realidad en su conjunto. Dentro de esta, los de nuestra vida humana (algunas propuestas se limitan a ella). Dentro de esta, a su vez, los de dimensiones concretas de lo humano, como, por ejemplo, la sexualidad o la relación con la naturaleza. Pueden ser seculares, sin implicaciones transmundanas (como, por ejemplo, cierto modo de entender la llamada ecología profunda), o religiosos (en todas las religiones anida una propuesta de sentido). Hay también propuestas que expresan el sinsentido, el absurdo de la realidad (humana).

Hay conexiones fácticas con propuestas de ( $\sin )$ sentido en la vida de todos los humanos: más o menos conscientes, más o menos coherentes, más o menos sostenidas en el tiempo, más o menos personalizadas y elegidas. Estas conexiones condicionan, inspiran, fundamentan, alientan, orientan los proyectos de vida realizada que hacemos, 
en concreto, sus fines, sus valores, sus planes. Es importante, por eso, que, al considerarlos, hagamos claridad sobre esos referentes de sentido y de plenitud en los que nos insertamos y los insertamos, a fin de optar con libertad lúcida y crítica por aquellos que se nos muestren más consistentes. Aparte de que vivir coherentemente la referencia a un sentido concreto de la realidad puede ser considerado por sí mismo una dimensión clave de nuestro proyecto vital.

Hay que ser conscientes, de todos modos, de que se da una circularidad entre nuestros proyectos de vida y nuestras opciones de valor y de sentido. Por ejemplo, la relación que a través de esos proyectos mantenemos con el bien público, lo que perseguimos con una profesión, la conexión que establecemos entre consumo y felicidad, el tipo de vida sexual que anhelamos, etc., dependen de la jerarquización de los valores que hagamos y del sentido que demos a la vida y a la realidad. Pero, a su vez, la puesta en práctica de los planes de vida puede afianzar o modificar nuestros mundos de sentido, con sus jerarquías de valores.

Ante las opciones de valor y de sentido que podamos hacer, lo deontológico de la ética: a) por un lado, impone límites a la pluralidad de ellas: no deben dañar el valor de la dignidad de nadie, incluido el de quienes las asumen, y una de las razones a su favor en el diálogo entre ellas será el que lo alienten expresamente; b) por otro lado, hace legítimas todas las opciones que respeten ese criterio de la dignidad, tanto en el mundo de sentido que ofrecen como en la jerarquización de valores que tal sentido implica. Esto se aplica por igual a propuestas estrictamente seculares, a las abiertas genéricamente a la espiritualidad, a las ligadas expresamente a una confesión religiosa.

La socialización primaria, en la infancia y adolescencia, necesaria para hacernos efectivamente humanos, implica siempre una socialización en mundos de sentido, con su correspondiente jerarquía de valores. Puede buscarse expresamente socializar en alguno de ellos, pero también se socializa implícitamente en mundos de sentido de los que no somos muy conscientes. Habiendo múltiples agentes socializadores, que pueden divergir en sus propuestas y en la conciencia de ellas: la familia, la escuela, otros grupos formativos, los grupos de afines, los medios de comunicación en su sentido más amplio, etc. La inhibición en la socialización en mundos de sentido decidida por unos agentes (por ejemplo, la familia) solo significa que la socialización de otros tenderá a influir más.

Ante esta realidad: a) es legítimo proponerse realizar una socialización determinada -por ejemplo, en la familia-, siempre que su contenido esté legitimado éticamente y se ofrezca en modos tales que no solo dejen espacio a la libertad receptivocrítica que se vaya adquiriendo con el avance de la edad, sino que además persigan expresamente aumentar la capacidad de ella; b) una de las tareas relevantes de maduración en la autonomía de las personas tiene que ver con esta progresiva receptividad crítica, de modo tal que lo que realmente acabemos interiorizando como mundos de sentido y jerarquía de valores "nuestros" sea lo que decidamos personalmente asumir de modo personalizado, con el discernimiento correspondiente; c) todos los agentes socializadores efectivos tendrían que proponerse integrar en la socialización los valores que deben compartir todas las propuestas de sentido, los ligados a la dignidad, y algunos de ellos, en especial la escuela, pueden optar por focalizarse en 
esta socialización -si es pública, debe hacerlo-, manteniéndose imparciales ante las propuestas de sentido.

2. Las relaciones de apoyo a las personas con discapacidad intelectual ¿deben tener presentes estas cuestiones? Dado que son una realidad en todos los humanos y marcan sus proyectos de vida - por tanto, también en los de estas personas y en sus proyectos-, la respuesta espontánea es que sí. Este es, de todos modos, un tema delicado, porque se presta al irrespeto en su forma de "adoctrinamiento" que manipula la libertad y hiere la dignidad de la persona apoyada. Ante ello, avanzaré diversas sugerencias, que propongo como incompletas y provisionales, necesitadas de contrastación dialogada.

Como punto de arranque no debe ignorarse que: a) la cuestión planteada es clave para la persona que busca su realización, pero también para las relaciones interpersonales y ciudadanas, así como para la aceptación y apoyo de la ética cívica; b) como se ha indicado, es ingenuo proponerse: "no socialicemos en nada y que cada uno, con la maduración de su libertad, vaya eligiendo lo que quiera”, porque nadie elige sobre vacío, sino en contextos culturales precisos, con sus propuestas (Taylor, 1994) y siempre hay agentes socializadores -a veces, dominantemente, en la forma confusa pero eficaz de "socialización ambiental"- en nuestros referentes primarios para las elecciones. Quienes tienen relaciones de apoyo y acompañamiento a personas con discapacidad deben asumir esta realidad y encontrar su lugar en ella.

Quienes intervienen conscientemente en la socialización de estas personas no tienen que olvidar la exigencia de incluir en esa socialización, en los modos que se correspondan con sus diversas funciones, la dimensión deontológica cívicamente obligante de ella, la basada en la dignidad y el correspondiente respeto positivo -el que incluye la justicia social-, que tiene que modular las jerarquías de valores dependientes de los mundos de sentido y los proyectos de vida que de modos expresos o indirectos se remitirán a ellos.

Las organizaciones que apoyan a las personas con discapacidad intelectual deben decidir si al atender a estas se limitan como tales a la socialización común en la dignidad y los derechos humanos, manteniéndose neutrales e imparciales ante las propuestas densas de sentido, o si, no siendo públicas, asumen como inspiración de sus actividades una de estas propuestas, haciéndolo del conocimiento de todos por exigencias éticas de transparencia. Si son neutrales frente a los mundos de sentido de sus miembros, gestores y profesionales, en sus diseños de actividades y acompañamientos, deben mostrarse también neutrales -empáticamente respetuosos- en todo lo que tenga que ver con su actividad en cuanto profesionales, poniendo entre paréntesis sus opciones personales de sentido. A la vez, deben impulsar ese mismo respeto entre las personas que conviven en los centros de la organización.

En principio, para quien recibe apoyos, puede ser conveniente estar abierto a la posibilidad de disfrutar de un acompañamiento respetuoso en su discernimiento de los mundos de sentido, como expresión relevante de la maduración de su libertad y como ocasión para el enriquecimiento personal y de sus proyectos de vida. Pero habría que precisar quiénes tienen que ofrecerlo, dónde y sobre qué. Con esto se sugiere 
que en el abordaje de la temática que se va señalando pueden hacerse distinciones entre los agentes de apoyo, en concreto entre: a) las familias y las organizaciones de sentido, como, por ejemplo, las Iglesias a las que las familias puedan pertenecer, que pueden ser más proactivas en el acompañamiento de las vivencias de sentido; y b) las organizaciones de apoyo a las personas con discapacidad y los profesionales pertenecientes a estas, que pueden ceñirse a la socialización de los valores cívicos. Sobre la base de la comunicación y entendimiento mutuos.

Por último, hay que tratar de alentar el desarrollo evolutivo de las personas con discapacidad intelectual en este terreno de forma tal que, entrando progresivamente y sin retrasos forzados en la "adultez", de lo que se trate en los apoyos a ellas sea decisivamente de la facilitación de posibles diálogos, entre sujetos libres que los deseen, sobre sus mundos de sentido y sus jerarquías de valores. Evidentemente, haciéndose cargo de las realidades de limitación cognitiva que puedan darse en las personas.

3. La relevancia y practicidad de todas estas consideraciones se percibe cuando se abordan cuestiones concretas e importantes, como, por ejemplo, el acompañamiento en los proyectos vitales en el ámbito de la vida sexual. Es común en nuestras propuestas de apoyo hacer una presentación interesante pero parcial de este, a veces con alguna confusión, como cuando se denomina "modelo moral" -rechazándolo-, que es identificado con el control y la represión de la sexualidad de las personas por reducir la legitimidad del ejercicio de esta al matrimonio heterosexual y orientado a la procreación (López, 2006). Este es un modelo legítimo si es situado en el campo opcional del sentido y acepta la legitimidad de los otros modelos, pero es inmoral si pretende situarse en el campo de la ética de obligatoriedad universal; tiene, evidentemente, una dimensión "moral", pero como la tienen todos los modelos.

Un acercamiento global a la sexualidad cuando es contemplada en los proyectos de vida - por la persona interesada y por quienes le apoyan- debe considerar en su interrelación: a) la dimensión científica, desde la que aclarar realidades fácticas sobre las que asentarlo todo, por ejemplo, la distinción, con su pluralidad interna, entre sexo biológico que se tiene al nacer; identidad de género con la que nos identificamos, que no necesariamente coincide con el sexo biológico, y orientación sexual; b) la dimensión deontológica de los preceptos éticos obligantes para todos en toda relación sexual, aglutinada en torno al respeto a la dignidad: respeto a las personas con las que interactuamos sexualmente y respeto a las identidades y a las orientaciones sexuales; c) la dimensión de sentido (simbólica) de la sexualidad, que nos adentra en el plural mundo del sentido al que la remitimos como campo para nuestras opciones, en el que no cabe la imposición sino la elección personal, abierta al diálogo desprejuiciado y respetuoso sobre la mayor o menor plenificación que aporta cada una de las propuestas. Aquí aparecen clásicos modelos como el de la ley natural -el antes citado-, el de la fidelidad de pareja, el de la pasión, el de la libertad del deseo compartido, el polémico de la prostitución no forzada (trabajo sexual); y emergen modelos nuevos sujetos a discusión como el de la asistencia sexual o el más polémico de la sexualidad con robots androides. Son modelos, todos ellos, que en unos casos se enmarcan en mundos de sentido religiosos y en otros no. Como se ve, es un ámbito complejo que 
aquí queda solo apuntado, pero que muestra a las claras la pertinencia de considerar en los proyectos de vida los referentes del sentido, también cuando acompañamos a las personas con discapacidad intelectual.

\section{Para concluir}

Ha podido constatarse que el acompañamiento aquí considerado en el diseño y realización de los proyectos vitales de las personas acompañadas es a la vez relevante y delicado. Más que repetir ahora, para finalizar, sus amplias coordenadas, creo oportuno destacar la importancia de conseguir que afiance, como sustrato de todo, la estima de sí, o relación positiva consigo mismo de cada persona, como sujeto capaz de una iniciativa que sabe combinar con la recepción de apoyos, con la que va construyendo, precisamente a través del cumplimiento razonable de sus proyectos que implican a los otros, una identidad consistente en la que se reconoce con satisfacción, con gozo.

\section{Referencias bibliográficas}

Aristóteles (1988). Ética Nicomáquea y Ética Eudemia. Madrid: Gredos.

CAmps, V. (1990). Virtudes públicas. Madrid: Espasa.

Comte-Sponville, A. (1998). Pequeño tratado de las grandes virtudes. Madrid: Espasa Calpe.

ETXEBERRIA, X. (2005). Virtudes y trato diario con las personas con discapacidad. En X. ETXEBERria (Ed.), Aproximación ética a la discapacidad (pp. 61-92). Bilbao: Universidad de Deusto.

ETXEBERRIA, X. (2012). Virtudes para convivir. Madrid: PPC.

ETXEBERria, X. (2016). Autonomía y decisiones de representación/sustitución en personas con discapacidad intelectual: Perspectiva ética. Siglo Cero, 47 (1), 55-66.

García Marza, D. (1992). Ética de la justicia. Madrid: Tecnos.

Habermas, J. (1991). Conciencia moral y acción comunicativa. Barcelona: Península.

KANT, I. (1973). Fundamentación de la metafísica de las costumbres. Madrid: Espasa Calpe.

López, F. (2006). La educación sexual de personas con discapacidad. Siglo Cero, 37 (1), 5-22.

MacInTyre, A. (1987). Tras la virtud. Barcelona: Crítica.

MacIntyre, A. (2001). Animales racionales y dependientes: por qué los seres bumanos necesitamos las virtudes. Barcelona: Paidós.

Rawls, J. (1979). Teoría de la justicia. Madrid: Fondo de Cultura Económica.

Ricoeur, P. (1996). Sí mismo como otro. Madrid: Siglo XXI.

TAylor, C. (1994). Ética de la autenticidad. Barcelona: Paidós.

Thiebaut, C. (2005). Prudencia. En P. Cerezo (Ed.), Democracia y virtudes cívicas (pp. 77107). Madrid: Biblioteca Nueva. 